\title{
The iron-regulatory peptide hormone hepcidin: expression and cellular localization in the mammalian kidney
}

\author{
H Kulaksiz ${ }^{*}$ F Theilig ${ }^{1, *}$, S Bachmann ${ }^{1}$, S G Gehrke, D Rost, \\ A Janetzko ${ }^{3}$, Y Cetin ${ }^{2}$ and W Stremmel
}

\author{
Department of Internal Medicine, Division of Gastroenterology, Im Neuenheimer Feld 410, University Hospital Heidelberg, D-69121 Heidelberg, Germany \\ ${ }^{1}$ Institute of Anatomy, Charite, Humboldt University, Berlin, Germany \\ ${ }^{2}$ Institute of Anatomy and Cell Biology, Philipps-University Marburg, Germany \\ ${ }^{3}$ DRG Instruments GmbH, Marburg, Germany \\ (Requests for offprints should be addressed to H Kulaksiz; Email: Hasan.Kulaksiz@med.uni-heidelberg.de) \\ *(H Kulaksiz and F Theilig contributed equally to this work)
}

\begin{abstract}
It is generally accepted that iron homeostasis is mainly controlled in the gastrointestinal tract by absorption of dietary iron. However, recent studies have shown that the kidneys are also involved in iron metabolism. Since the iron-regulatory and antimicrobial peptide hormone hepcidin was originally isolated from human urine we have investigated the expression as well as the zonal and cellular localization of hepcidin in the mammalian kidney and developed an ELISA assay to analyze hepcidin concentrations in serum and urine. The expression of hepcidin was shown by RT-PCR and immunoblot experiments; its cellular localization was studied by immunocytochemistry in human, mouse and rat kidney, which revealed similar patterns of immunoreactivity. Hepcidin expression was absent from the proximal tubule and descending and ascending thin limbs. There was strong expression in the thick ascending limb of the cortex and in connecting tubules. Moderate expression was noted in the thick
\end{abstract}

ascending limb and collecting ducts of the medulla and in collecting ducts of the papilla. Importantly, the cells of the macula densa were unstained. At the cellular level, hepcidin was localized to the apical cell pole of the renal epithelial cells. Based on its presence in urine, hepcidin may be released apically into the urine. Enhanced levels of hepcidin were determined in patients with chronic renal insufficiency $(156 \cdot 8 \mathrm{ng} / \mathrm{ml}$, controls $104.2 \mathrm{ng} / \mathrm{ml})$ indicating that the kidneys may metabolize and/or eliminate the circulating peptide. From the expression of hepcidin in the mammalian kidney, we have concluded that the ironregulatory hormone is an intrinsic renal peptide which is not only eliminated by the kidney but is also synthesized in the kidney tubular system. Localization of hepcidin in the kidney implicates an iron-regulatory role of this peptide hormone in the renal tubular system, possibly in connection with the iron transporter divalent metal transporter-1. Journal of Endocrinology (2005) 184, 361-370

\section{Introduction}

Hepcidin is a recently discovered peptide hormone that was isolated from human urine (Park et al. 2001) and blood (Krause et al. 2000) and was found to exhibit antibacterial and antifungal activity. From human urine, two predominant forms, hepcidin-20 and hepcidin-25, differing by amino-terminal truncation, were characterized as 20 and 25 amino acid (aa) residues with 8 cysteines connected by intramolecular disulfide bonds (Park et al. 2001). A hepcidin cDNA encoding an 83 aa precursor in mice and an 84 aa precursor in rat and man, including a putative 24 aa signal peptide, was subsequently identified when searching for liver-specific genes that were regulated by iron (Pigeon et al. 2001). Hepcidin expression is abolished in mice exhibiting iron overload due to the targeted disruption of the upstream stimulatory factor 2 gene resembling the phenotype of hfe $-/-$ mice (Nicolas et al. 2001). In contrast, overexpression of hepcidin was shown to result in severe iron deficiency anemia in transgenic mice (Nicolas et al. 2002a), indicating that hepcidin plays a pivotal role in iron metabolism. Recent studies have found abnormal hepcidin expression and disrupted hepcidin regulation (Bridle et al. 2003, Kulaksiz et al. 2004) in hemochromatosis gene (HFE)-associated hemochromatosis and association of hepcidin mutations with severe juvenile hemochromatosis (Roetto et al. 2003). Based on these observations, it has been suggested that hepcidin is a key component of iron homeostasis that acts as a negative regulator of iron absorption in the small intestine and of iron release from macrophages (Nicolas et al. 2001, 2002a). 
While the majority of studies have concentrated on the regulation and function of this peptide hormone in the liver as the major site of hepcidin production (Park et al. 2001, Kulaksiz et al. 2004), accumulating data suggest that this bioactive peptide may also play a role in the kidney and urinary tract (Ferguson et al. 2003, Wareing et al. 2003, Kulaksiz et al. 2004). It is widely believed that iron homeostasis is mainly controlled in the gastrointestinal tract at the level of uptake from the diet. The current dogma is that there is no excretory route for iron in the organism. However, recent studies have shown that the kidney plays an important role in iron transport (Gunshin et al. 1997, Ferguson et al. 2003, Wareing et al. 2003); a significant proportion of iron in serum is available for ultrafiltration by the glomerulus and the majority of iron filtered at the glomerulus is reabsorbed (Wareing et al. 2000).

Hence, it is reasonable to analyze whether hepcidin is also present in the kidney as a local peptide. We have raised antisera against various epitopes of the hepcidin precursor molecule and investigated the expression of hepcidin in the kidney of three mammalian species at RNA and protein level. Our findings indicate that, beside its elimination in the kidney, hepcidin is also produced as an intrinsic peptide in the tubular cells of the mammalian kidney. Its presence at the apical cell pole suggests that it might be released luminally into the urine, implicating a regulatory role for hepcidin in the kidney and/or urinary tract.

\section{Materials and Methods}

\section{Tissues and tissue preparation}

Human kidney samples $(n=5)$ were obtained after kidney resection in adult patients with hypernephroma. Human liver samples $(n=7)$ were obtained after hemihepatectomy in adult patients with liver metastases (Kulaksiz et al. 2004). The ethics committee of University Hospital Heidelberg approved the study, and experiments were undertaken in accordance with the Helsinki Declaration of 1975. All patients had given written permission for the use of the tissue for research purposes. Healthy tissues were fixed in 4\% paraformaldehyde or in Bouin's fixative for immunohistochemistry or immediately frozen in liquid nitrogen for RT-PCR and immunoblot.

For RT-PCR and immunoblot analysis, rats $(n=5)$ and mice $(n=5)$ were anesthetized and killed by cervical dislocation. For biochemical analysis, tissue specimens from kidney and liver were obtained and immediately frozen in liquid nitrogen. For immunohistochemical analysis, kidneys of rats and mice were perfused retrogradely through the abdominal aorta using phosphatebuffered saline (PBS) adjusted to $330 \mathrm{mosmol} / \mathrm{kg} \mathrm{H} \mathrm{H}_{2} \mathrm{O}$ with sucrose, $\mathrm{pH} 7 \cdot 4$, for $20 \mathrm{~s}$. Next, a solution of $3 \%$ paraformaldehyde in PBS was infused for 5 min, followed by PBS adjusted to $330 \mathrm{mosmol} / \mathrm{kg} \mathrm{H}_{2} \mathrm{O}$ for $1 \mathrm{~min}$. Kidneys were removed and protected from freezing artifacts by subsequent overnight immersion in PBS adjusted to $800 \mathrm{mosmol} / \mathrm{kg} \mathrm{H}_{2} \mathrm{O}$ by sucrose ( $\mathrm{pH} \mathrm{7 \cdot 3}$ ), shockfrozen and stored at $-80{ }^{\circ} \mathrm{C}$ for subsequent cryostat sectioning.

Peptide synthesis, immunization procedure and antibodies

From the published pro-hepcidin sequence (Krause et al. 2000, Pigeon et al. 2001), the peptides hepcidin(28-47) and hepcidin-(70-84) were synthesized as C-terminal amides using a standard Fmoc (N-alpha-(9fluorenylmethyloxycarbonyl)) protocol (Kulaksiz et al. 2002a,b). Peptides were coupled to keyhole limpet hemocyanin using m-maleimidobenzoyl-N-hydroxysuccinimide ester, and two SPF rabbits (Charles River-Iffa Credo, Wilmington, MA, USA) were immunized with each peptide conjugate (Eurogentec, Seraing, Belgium). The antibodies EG(1)-HepC, EG(2)-HepC (each directed against pro-hepcidin-(70-84)) and EG(1)-HepN and EG(2)-HepN (each directed against pro-hepcidin$(28-47))$ have been generated and characterized elsewhere (Kulaksiz et al. 2004).

The antibodies employed for identification of kidney structures have been characterized and used previously (Tian et al. 2004).

\section{Expression analyses in the kidney}

Based on the GenBank cDNA sequences, the following primers were constructed and used: human hepcidin (database accession number NM021175) given in $5^{\prime}-3^{\prime}$ orientation, 5'-CTG CAA CCC CAG GAC AGA G-3' and 5'-GGA ATA AAT AAG GAA GGG AGG GG-3'; rat hepcidin (number NM 053469), 5'-ACA GAA GGC AAG ATG GCA CT-3' and 5'-GAA GTT GGT GTC TCG CTT CC-3', mouse hepcidin-1 (number NM 032541), 5'-CGA TAC CAA TGC AGA AGA GAA GG-3' and 5'-TTC AAG GTC ATT GGT GGG GA-3'. The primers displayed no homology to any previously reported sequences.

RNA isolation was performed using Qiagen (Valencia, CA, USA) RNAeasy kit including DNA digestion. RTPCR analysis was performed as described previously (Kulaksiz et al. 2002a,b). After an initial denaturation of $94{ }^{\circ} \mathrm{C}$ for $4 \mathrm{~min}$, reactions were subjected to 30 cycles of the following thermal program: $94^{\circ} \mathrm{C}$ for $30 \mathrm{~s}, 60^{\circ} \mathrm{C}$ for $30 \mathrm{~s}$ and $72^{\circ} \mathrm{C}$ for $30 \mathrm{~s}$; this program was followed by a final 5-min elongation step at $72{ }^{\circ} \mathrm{C}$. Amplification products were run on an ethidium bromide-stained $1.8 \%$ $89 \mathrm{mM}$ Tris/89 $\mathrm{mM}$ boric acid/2 mM EDTA (pH 8.3) agarose gel. As a control for specificity, the amplified PCR products were sequenced by MWG-Biotech (Ebersberg, Germany). 
Table 1 Precision of the ELISA

\begin{tabular}{|c|c|c|c|c|c|c|}
\hline & \multicolumn{3}{|c|}{ Intra-assay } & \multicolumn{3}{|c|}{ Interassay } \\
\hline & $n$ & $\begin{array}{l}\text { Mean } \pm \text { S.D. } \\
(\mathrm{ng} / \mathrm{ml})\end{array}$ & $\begin{array}{l}\text { C.V. } \\
(\%)\end{array}$ & $n$ & $\begin{array}{l}\text { Mean } \pm \text { S.D. } \\
(\mathrm{ng} / \mathrm{ml})\end{array}$ & $\begin{array}{l}\text { C.V. } \\
(\%)\end{array}$ \\
\hline Serum & & & & & & \\
\hline 1 & 12 & $426 \cdot 7 \pm 20 \cdot 2$ & $4 \cdot 69$ & 23 & $431.96 \pm 20 \cdot 8$ & $4 \cdot 82$ \\
\hline 2 & 12 & $210 \cdot 7 \pm 8 \cdot 58$ & $4 \cdot 07$ & 23 & $216 \cdot 17 \pm 14 \cdot 44$ & $6 \cdot 68$ \\
\hline 3 & 12 & $110 \cdot 7 \pm 4 \cdot 74$ & $4 \cdot 28$ & 23 & $109 \cdot 8 \pm 10 \cdot 72$ & $9 \cdot 76$ \\
\hline
\end{tabular}

\section{Immunoblot analysis}

Immunoblot experiments were performed on $16.5 \%$ tricine-SDS-polyacrylamide gels. Proteins from human, mouse and rat kidney and liver, as well as from human urine $(50 \mathrm{ml}$ for each experiment) were extracted according to the published protocols (Kulaksiz et al. 2002a,b, 2004). Following electrophoresis, proteins were transferred onto hydrophobic polyvinylidene fluoride-based membranes (Pall, Portsmouth, Hants, UK) by semidry blotting. The membranes were incubated overnight with hepcidin antibodies diluted 1:1000. After washing in Tris-buffered saline containing $10 \mathrm{mM}$ Tris- $\mathrm{HCl}(\mathrm{pH} 8 \cdot 0), 150 \mathrm{mM}$ $\mathrm{NaCl}$ and $0.05 \%$ Tween 20 , immunoreactive proteins were visualized after incubation with alkaline phosphatase-conjugated goat anti-rabbit antibody (diluted 1:50 000; Sigma) using nitro blue tetrazolium and 5-bromo-4-chloro-3-indolyl phosphate as chromogens (Sigma). The immunoreaction on the immunoblot was specifically blocked after preincubation of the antibodies with the corresponding peptide immunogens. Crossreactivity with the second goat anti-rabbit antibody was excluded by appropriate controls (Kulaksiz et al. 2002a,b).

\section{Immunocytochemical protocol}

Five micrometer thick cryostat sections were used. After

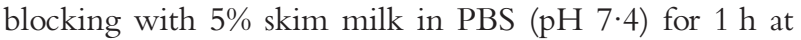
room temperature, sections were incubated with primary antibody for $2 \mathrm{~h}$ at room temperature and then overnight at $4{ }^{\circ} \mathrm{C}$, followed by incubation with fluorochromecoupled secondary antibody. For double-labeling, suitable secondary antibodies coupled to different fluorochromes were applied (Dianova, Hamburg, Germany), or serial sections were used. Slides were evaluated with a digital camera (Spot; Diagnostic Instruments), processed with MetaVue software (Universal Imaging; Visitron, Puchheim, Germany) and viewed with a Leica light microscope equipped with an high pressure fluorescence lamp.

Immunoperoxidase staining Tissues were fixed in $4 \%$ paraformaldehyde for $18 \mathrm{~h}$ at $4{ }^{\circ} \mathrm{C}$ and embedded in paraffin. Paraffin sections $(4-5 \mu \mathrm{m})$ were immunostained for hepcidin (antibodies EG(1)-HepN, EG(2)-HepN,
EG(1)-HepC and EG(2)-HepC, each diluted 1:2000) by the avidin-biotin-peroxidase complex technique as detailed elsewhere (Kulaksiz et al. 2002a,b, 2004).

With respect to the immunoreactivities obtained, nonspecificities in the immunohistochemical protocol were excluded by running the following controls: (a) omission of single steps in the immunohistochemical protocol, (b) addition of polylysine $\left(M_{\mathrm{r}} 15000 ; 2 \mathrm{mg} / \mathrm{ml}\right.$; Sigma) to the first antibody and (c) use of high molar (0.5 M) PBS as a rinsing solution between the various steps of the immunohistochemical protocol. Antibody specificities were tested by preadsorption of the antibodies with homologous and heterologous antigenic peptides $(6 \cdot 25-100 \mu \mathrm{g} / \mathrm{ml}$ of the antiserum) (Kulaksiz et al. 2002a,b). Preadsorption of the antibodies with homologous antigens at concentrations as low as $6.25 \mu \mathrm{g} / \mathrm{ml}$ completely blocked immunostaining in the kidney, while preadsorption of the antibodies with heterologous antigens at concentrations up to $100 \mu \mathrm{g} / \mathrm{ml}$ had no effect on immunostaining.

\section{Hepcidin ELISA competitive binding assay}

The ELISA has been characterized and used previously (Kulaksiz et al. 2004).

The analytical sensitivity was calculated from the mean minus 2 S.D. (S.D. $=0 \cdot 055)$ of 21 replicates $(n=21)$ analysis of zero standard. The sensitivity of the assay is $3.95 \mathrm{ng} / \mathrm{ml}$. Precision, recovery tests and dilution tests are described in Tables $1-3$ respectively.

Serum and urine samples were obtained from 22 individuals (11 women and 11 men, aged 23-59 years, mean 39 years) and serum samples were obtained from 22 patients with renal insufficiency undergoing chronic

Table 2 ELISA recovery test

\begin{tabular}{|c|c|c|c|}
\hline & $\begin{array}{l}\text { Endogenous } \\
\text { hepcidin } \\
(\mathrm{ng} / \mathrm{ml})\end{array}$ & $\begin{array}{l}\text { Average } \\
\text { recovery } \\
(\%)\end{array}$ & $\begin{array}{l}\text { Range of } \\
\text { recovery } \\
(\%)\end{array}$ \\
\hline Serum & & & \\
\hline 1 & $273 \cdot 8$ & $93 \cdot 1$ & $91 \cdot 8-94 \cdot 3$ \\
\hline 2 & $116 \cdot 8$ & $94 \cdot 7$ & $89 \cdot 2-98 \cdot 7$ \\
\hline 3 & $82 \cdot 3$ & $97 \cdot 1$ & $94 \cdot 5-105 \cdot 7$ \\
\hline
\end{tabular}

Journal of Endocrinology (2005) 184, 361-370

Downloaded from Bioscientifica.com at 04/26/2023 12:31:10PM via free access 
Table 3 ELISA dilution test

\begin{tabular}{|c|c|c|c|}
\hline & $\begin{array}{l}\text { Endogenous } \\
\text { hepcidin } \\
\text { (ng/ml) }\end{array}$ & $\begin{array}{l}\text { Average } \\
\text { recovery } \\
(\%)\end{array}$ & $\begin{array}{l}\text { Range of } \\
\text { recovery } \\
(\%)\end{array}$ \\
\hline Serum & & & \\
\hline 1 & $591 \cdot 6$ & $99 \cdot 1$ & $90 \cdot 6-108 \cdot 2$ \\
\hline 2 & $157 \cdot 5$ & $107 \cdot 9$ & $106 \cdot 3-107 \cdot 2$ \\
\hline 3 & $179 \cdot 4$ & $104 \cdot 6$ & $92 \cdot 3-111 \cdot 6$ \\
\hline
\end{tabular}

hemodialysis (11 women and 11 men, aged 25-77 years, mean 48 years). All patients with chronic renal insufficiency were treated two to three times a week with 3000 IU recombinant human erythropoietin (HoffmannLa Roche, Grenzach-Whylen, Germany). During sample collection, healthy volunteers and patients had no infection and no bleeding. Ten milliliter blood samples were withdrawn into serum tubes and $10 \mathrm{ml}$ urine samples were also collected in urine tubes and centrifuged at $2500 \mathrm{~g}$ for $10 \mathrm{~min}$ at $4{ }^{\circ} \mathrm{C}$. Determinations were performed in duplicate using 96-well microtiter plates as described (Kulaksiz et al. 2004). In brief, microtiter plates were coated with $200 \mu \mathrm{l} /$ well rabbit anti-hepcidin antibody EG(2)-HepN diluted 1:4000. Fifty microliter standards containing various amounts of synthetic peptides $(0,20,100,500$ and $1000 \mathrm{ng} / \mathrm{ml}$ ) or human serum and urine samples and $150 \mu \mathrm{l} \quad$ N-terminally biotinylated hepcidin-(28-47) (Peptide Speciality Laboratories $\mathrm{GmbH}$, Heidelberg, Germany; 2 ng/well) were added to each well and incubated for $1 \mathrm{~h}$ at room temperature. After washing with TBS with $0.05 \%$ Tween 20 , the biotinylated antigenantibody complexes were detected by streptavidinperoxidase enzyme (Dako, Hamburg, Germany) with the substrate tetramethylbenzidine (DRG Instruments $\mathrm{GmbH}$, Marburg, Germany); the color reaction was stoped with $1 \mathrm{M} \mathrm{H}_{2} \mathrm{SO}_{4}$ and the extinction of the solution was read at $450 / 630 \mathrm{~nm}$ wavelength.

\section{Statistics}

Possible differences between the groups were analyzed using the ANOVA method with pairwise $t$-tests after global evaluation. Differences were considered as significant at $P<0 \cdot 05$.

\section{Results}

Expression of hepcidin in the mammalian kidney

RT-PCR analysis revealed clear expression of hepcidin not only in the liver (positive control, data not shown; see Kulaksiz et al. 2004), but also in human, rat and mouse kidney (Fig. 1). A $192 \mathrm{bp}$ expected PCR product for human, a $193 \mathrm{bp}$ product for mouse and a $201 \mathrm{bp}$ product for rat were detected in the liver (data not shown) and kidney of these species. The sequence analysis revealed that the PCR-generated products had a complete homology with the cDNAs of the corresponding peptides.

At the translational level, the presence of hepcidin was confirmed by immunoblot studies with region-specific antibodies (Fig. 1). Antisera directed against the $\mathrm{C}$ and $\mathrm{N}$ terminus of the hepcidin precursor molecule coincidentally identified an immunoreactive band of $\sim 9.5 \mathrm{kDa}$ in extracts of human, rat and mouse kidney.

\section{Cellular localization of hepcidin}

Identification of kidney structures For a precise assignment of hepcidin synthesis to identified portions of the renal tubule, we used morphological criteria as well as the segmental coexpression of defined markers (Bachmann

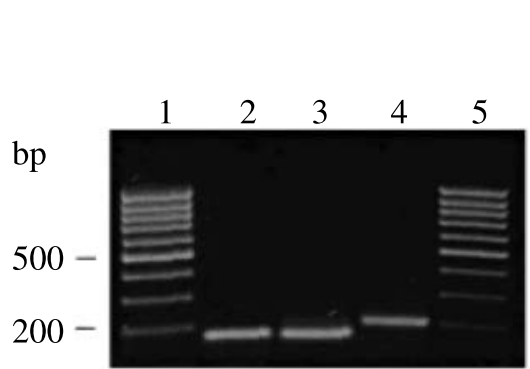

(A)

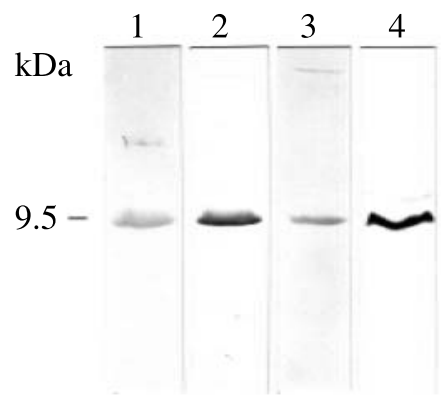

(B)

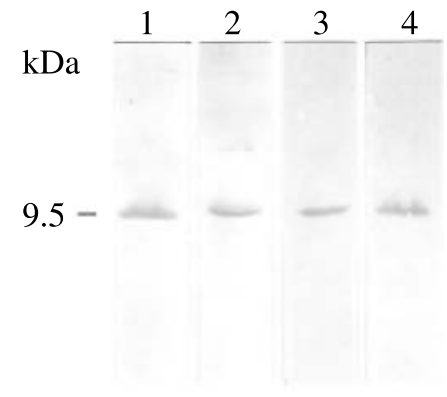

(C)

Figure 1 (A) RT-PCR analyses of human (lane 2), mouse (lane 3) and rat (lane 4) kidney hepcidin expression. A bp DNA ladder is indicated (lanes 1 and 5). (B and C) Immunoblot analyses of hepcidin in extracts of human (lanes 1), rat (lanes 2) and mouse (lanes 3) kidney, as well as in human urine (lanes 4) with (B) N-terminal and (C) C-terminal antibodies. Note the immunoreactive bands at 9.5 kDa obtained with both antibodies recognizing different epitopes in the hepcidin precursor. (Molecular mass markers used: phosphorylase B, 105 kDa; glutamic dehydrogenase, 53 kDa; carbonic anhydrase, 34 kDa; myoglobin-blue, 23 kDa; myoglobin-red, $17 \mathrm{kDa}$; lysozyme, $13 \mathrm{kDa}$; aprotinin, $7 \mathrm{kDa}$; insulin, $3 \mathrm{kDa}$.) 
et al. 1999, Campean et al. 2001). The proximal tubule was recognized by the presence of megalin and brush border; thin limbs and vasa recta by their location within the vascular bundles; medullary and cortical thick ascending limb (mTAL and cTAL respectively) by the presence, and macula densa by the absence, of Tamm-Horsfall protein (THP); distal convoluted tubule (DCT) by the presence of the $\mathrm{Na}^{+}-\mathrm{Cl}^{-}$cotransporter (NCC); and parts of the DCT and the connecting tubule (CNT) by
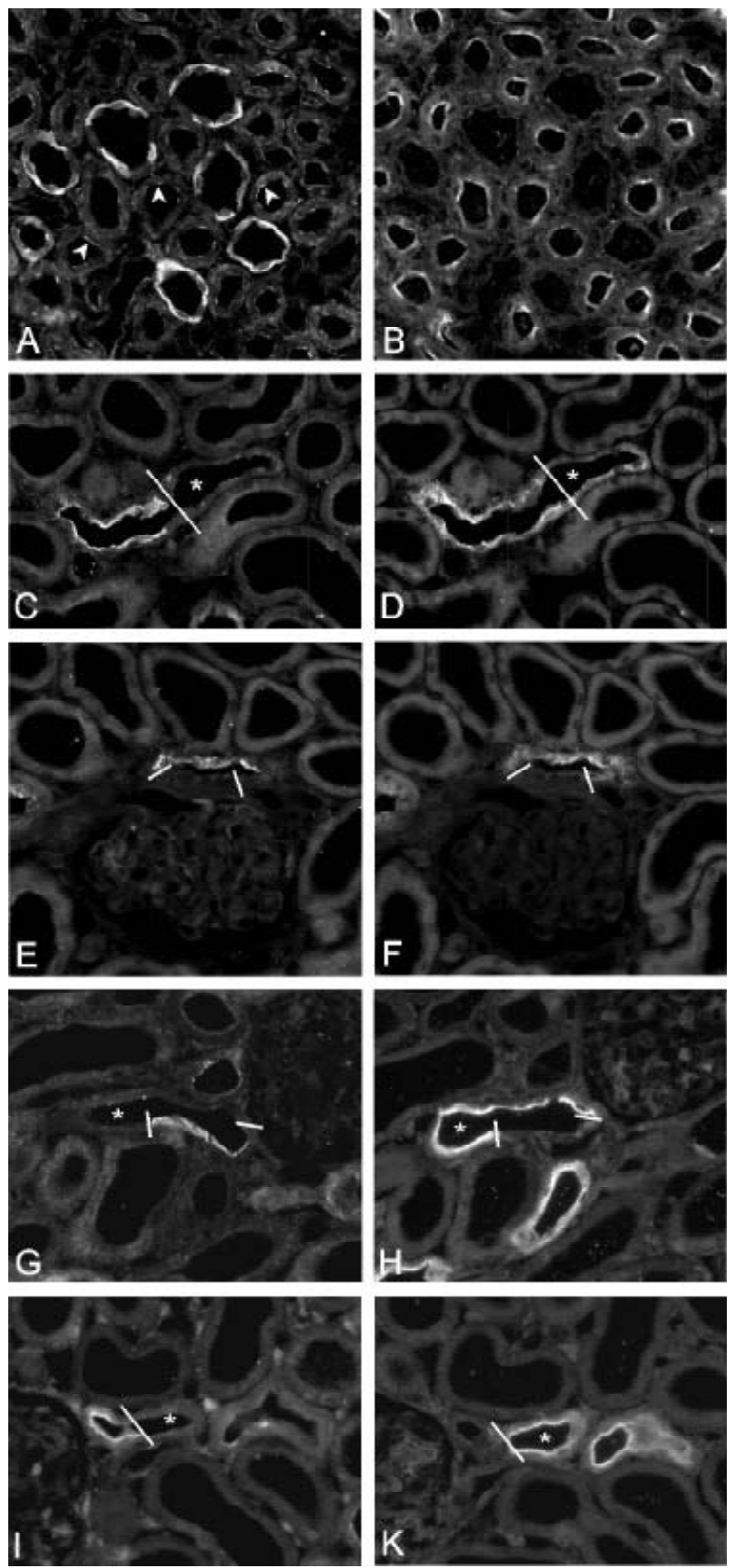

calbindin. Collecting ducts were identified by the presence of aquaporin-2 as well by the presence of intercalated cells.

Localization The distribution of immunoreactive hepcidin was analyzed using region-specific antibodies against the C-terminal and N-terminal portions of hepcidin. Staining with these antibodies showed an apical immunoreactive signal in the $\mathrm{MTAL}$ and cTAL and in the medullary collecting duct (MCD) of rats and mice. A more cytosolic localization was detected in the CNT and cortical collecting duct (CCD). Along the nephron, the onset of the hepcidin localization began with the onset of mTAL at the boundary between the inner medulla and the inner stripe of the outer medulla (Fig. 2A) as identified by the co-localization with THP (Fig. 2B). Signal continued the mTAL along the cortical border. The signal was faint but apically enhanced within the mTAL cells (arrows in Fig. 2A). In the cortex, stronger hepcidin immunoreactivity was found along some of the cTAL segments (Fig. 2C), but some were negative. In the positive cTAL portions, the signal ended at the transition to the DCT (Fig. 2C and D). Macula densa cells of the juxtaglomerular apparatus were identified by their microanatomical location and by the absence of THP; hepcidin was principally absent from these cells (Fig. 2E and F). Immunostaining of the DCT, as identified by staining with antibody to NCC in consecutive sections, was negative for hepcidin (Fig. $2 \mathrm{G}-\mathrm{K})$. These results were found with $\mathrm{N}$ - and C-terminal primary anti-hepcidin antibodies.

Antibody to calbindin, showing the signal beginning with the terminal DCT (DCT2 in rats; for review see Bachmann et al. 1999; data not shown) and continuing to the transition of the CNT to the collecting duct (Fig. $3 \mathrm{~A}-\mathrm{D})$, showed an overlap with anti-hepcidin as revealed by double-staining in the rat and the mouse using both $\mathrm{N}$ and C-terminal antibodies. Both hepcidin and calbindin were located only in the principal cells, whereas the intercalated cells were negative (arrowheads in Fig. 3E and F). The localization of hepcidin continued within the

Figure 2 Distribution of immunoreactive hepcidin in rat kidney ((A and I) C-terminal hepcidin antibody and (C, E and G) N-terminal hepcidin antibody)). For segment identification, double staining with anti-THP (B, D and $\mathrm{F}$ ) and staining in consecutive sections with anti-NCC ( $\mathrm{H}$ and $\mathrm{K}$ ) are shown. ( $\mathrm{A}$ and $\mathrm{B}$ ) Inner stripe of medulla showing faint hepcidin labeling at the luminal aspect (arrowheads) in TAL segments which are THP positive. A strong signal of MCD segments is shown in collecting ducts (see also Fig. 3). (C and D) The white lines indicate the junction between hepcidin- and THP-positive post-macula segment of TAL and hepcidin-negative, weakly THP-positive DCT (asterisks). (E and F) Hepcidin-positive, THP-positive TAL, opposite to macula densa (between the lines) showing the absence of hepcidin and THP. (G-K) Hepcidin-positive, NCC-negative staining of TAL between the lines and hepcidin-negative, NCC-positive staining of DCT (asterisks). Immunofluorescence microscopy using different fluorochromes. Magnification approximately $\times 400$. 
CCD and outer medullary collecting duct (OMCD) principal cells as shown by serial sectioning using antiaquaporin-2 (Fig. $3 \mathrm{G}$ and $\mathrm{H}$ ). In the papillary tip, antihepcidin labeling presented a weak apical staining in the inner medullary collecting duct (IMCD) cells as evaluated by double-labeling with aquaporin-2 (Fig. 3I and K).
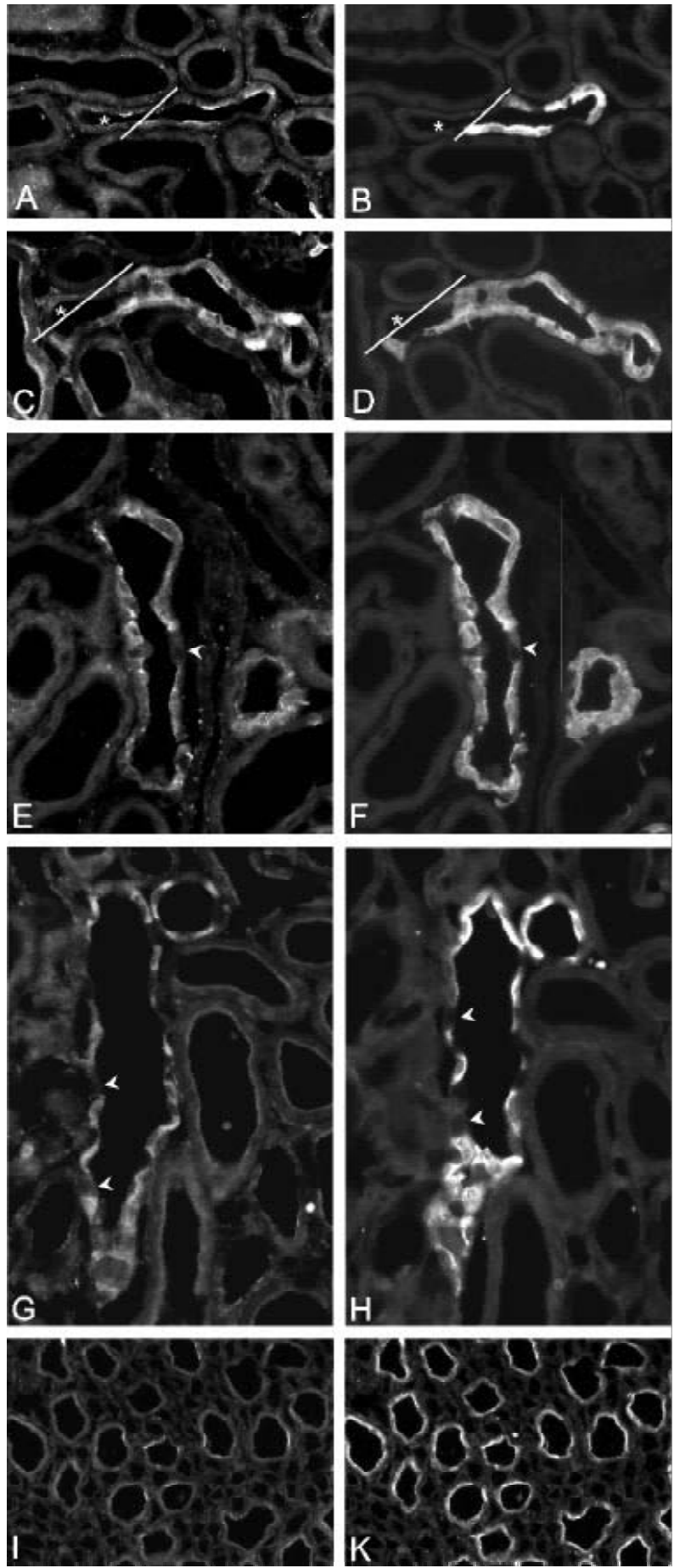

In human tissue, the localization of hepcidin revealed the same distribution pattern as in rats and mice. Positive staining with hepcidin antibodies showed labeling in the cTAL portion located opposite to the macula densa, as pointed out by arrowheads in Fig. 4A, whereas the macula densa cells were unreactive. Hepcidin-positive segments were also found in the vicinity of the cortical interlobular vein, suggesting that they were CNT segments (Fig. 4B and $\mathrm{C}$ ).

The distribution of immunoreactive hepcidin across the investigated species is summarized in Fig. 5.

\section{Detection of hepcidin prohormone in serum and urine}

A stable hepcidin ELISA assay with high reproducibility and sensitivity was developed with the specific N-terminal hepcidin antibody EG(2)-HepN (Kulaksiz et al. 2004). This antibody identifies pro-hepcidin; no ELISA assay exists at this time to detect the biologically active hepcidin-25. The ELISA employed revealed that prohepcidin is present in human serum. Pro-hepcidin was measured in the range from 68.5 to $139.2 \mathrm{ng} / \mathrm{ml}$ (means \pm s.E.; $104 \cdot 2 \pm 19 \cdot 5 \mathrm{ng} / \mathrm{ml}$ ) in the serum of healthy subjects. The pro-hepcidin concentrations varied from 63.9 to $327.3 \mathrm{ng} / \mathrm{ml}$ (means \pm S.E.; $156 \cdot 8 \pm 61.9 \mathrm{ng} / \mathrm{ml}$ ) in the serum of patients suffering from chronic renal insufficiency and were significantly increased compared with that in the control group. Using the sensitive hepcidin ELISA, pro-hepcidin was detected in human urine from the control group in the range from 13.9 to $456.0 \mathrm{ng} / \mathrm{ml}$ (means \pm S.E.; $180 \cdot 1 \pm 94 \cdot 8 \mathrm{ng} / \mathrm{ml}$ ). The presence of prohepcidin in human urine was also confirmed by immunoblot analysis. Hepcidin antisera identified in extracts of human urine a single immunoreactive band of $\sim 9.5 \mathrm{kDa}$ molecular mass that co-migrated exactly with the immunoreactive hepcidin in kidney tissues (Fig. 1).

\section{Discussion}

The recently discovered hormone hepcidin represents an antimicrobial peptide and a central regulator of iron

Figure 3 Distribution of immunoreactive hepcidin in rat kidney ((A and I) N-terminal hepcidin antibody and (C, E and G) C-terminal hepcidin antibody)). For segment identification, double staining with anti-calbindin (B, D and $F$ ), and staining in consecutive sections with anti-aquaporin-2 (AQP2) ( $\mathrm{H}$ and $\mathrm{K}$ ) are shown. (A-D) The white lines indicate the junction between mildly to strongly hepcidin-positive, strongly calbindin-positive CNT and weakly hepcidin-positive, calbindin-negative CCD (asterisks). (E and F) Hepcidin-positive, calbindin-positive CNT profiles showing absence of staining in intercalated cells (arrowheads). ( $\mathrm{G}$ and $\mathrm{H}$ ) Hepcidin-positive, AQP2-positive OMCD profiles showing absence of staining in intercalated cells (arrowheads). (I and K) Hepcidin-positive, AQP2-positive IMCD profiles. Both signals are apically enhanced. Immunofluorescence microscopy using different fluorochromes. Magnification approximately $\times 400$. 


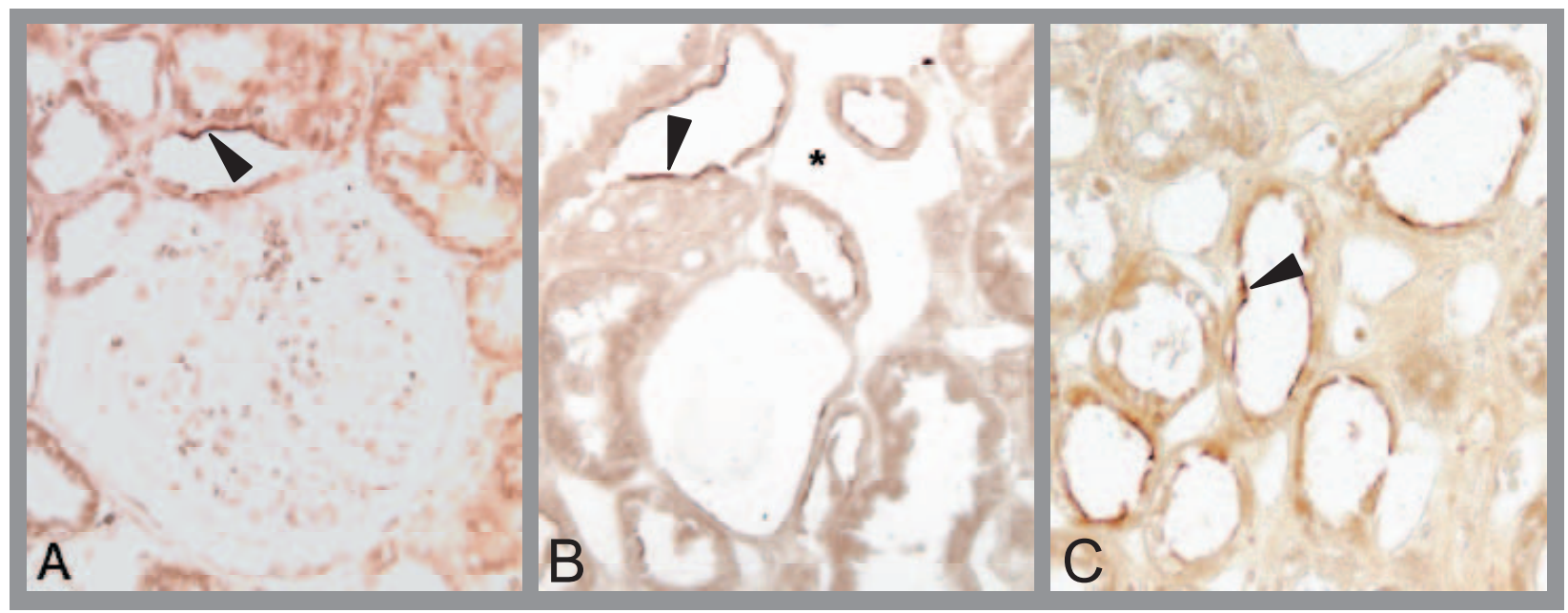

Figure 4 ( $\mathrm{A}$ and $\mathrm{B})$ Distribution of immunoreactive hepcidin in human kidney using antibody to the $\mathrm{N}$-terminal (A and B) and C-terminal (C) sequence. (A) Hepcidin-positive TAL (arrowheads) opposite to hepcidin-negative macula densa. (B) Hepcidin-positive CNT segments next to a cortical interlobular vein (asterisk). Staining is apically enhanced. (C) Hepcidin-positive distal tubules. Note the strong immunostaining at the apical pole of the epithelial cells (arrowheads). Immunoperoxidase staining. Magnification approximately $\times 450$.

homeostasis (Krause et al. 2000, Nicolas et al. 2001, 2002a, Park et al. 2001, Pigeon et al. 2001). In previous studies, it was shown that the liver is the main source of hepcidin (Park et al. 2001, Kulaksiz et al. 2004). Although hepcidin was originally isolated from human urine (Park et al. 2001) and hemofiltrate (Krause et al. 2000), no expression of this regulatory peptide has been described in the kidney (Pigeon et al. 2001).

Using the appropriate primer specifications and combinations successfully employed in the liver (Gehrke et al. 2003, Kulaksiz et al. 2004), the present RT-PCR analysis clearly revealed that hepcidin is not only expressed in the liver, but also in the kidney of three mammalian species human, rat and mouse. To verify the presence of the translated hepcidin peptide in the kidney, we raised different region-specific antisera against hepcidin and used them in immunoblot analysis and immunohistochemistry. Immunoblot analysis confirmed expression of hepcidin in the kidney. Four different antisera recognizing different epitopes in the hepcidin precursor molecule concurrently identified an immunoreactive peptide of $\sim 9.5 \mathrm{kDa}$ in the kidney of three different species, which corresponds to the predicted molecular mass of hepcidin prohormone deduced from the respective cDNA sequence (Pigeon et al. 2001). The apparent molecular mass of this immunoreactive peptide is also in accordance with the molecular mass of hepcidin prohormone detected in the liver (Kulaksiz et al. 2004). Our findings unequivocally demonstrated that hepcidin is not liver specific, but is also expressed in the kidney.

Immunocytochemical investigations with $\mathrm{N}$-terminal and C-terminal region-specific hepcidin antisera revealed that in human, mouse and rat kidney, the bioactive peptide is specifically localized to tubules of the renal cortex, medulla and papilla. Hepcidin immunoreactivity was strong in CTAL and CNT, moderate expression was found in MTAL, IMCD and collecting ducts of the papilla, which were identified by specific markers. The coincident staining by different region-specific antibodies not only in the human, but also in mouse and rat kidney assumes that these tubules are the actual source of renal hepcidin. No immunoreactivity for hepcidin was detected in the glomerulus, proximal tubule and descending and ascending thin limb. Moreover, macula densa cells of the juxtaglomerular apparatus, identified by their microanatomical location and by their absence of THP, and intercalated cells of CNT and MCD were unreactive for hepcidin.

In all zones of the kidney, hepcidin immunoreactivity was confined to epithelial cells. Remarkably, in the cortex strong hepcidin immunoreactivity was found along some of the cTAL segments, but some were completely negative. Distinct intercellular differences exist between the epithelial cells even of the same tubule with respect to the density of hepcidin immunoreactivity that may reflect intercellular differences in expression or secretion of hepcidin.

Conspicuously, in some tubules immunoreactivity for hepcidin was localized in the whole cytoplasm of the epithelial cells, whereas in other tubules hepcidin immunoreactivity was concentrated at the apical pole of the epithelial cells. In CNT and CCD, hepcidin antibodies produced a cytoplasmatic granular immunoreactivity pattern, assuming localization of the bioactive peptide in small secretory vesicles of the respective cells that have already been identified in these cells by electron microscopy (Brenner 2000). In mTAL, cTAL and MCD, hepcidin antibodies showed an immunoreactive signal at 


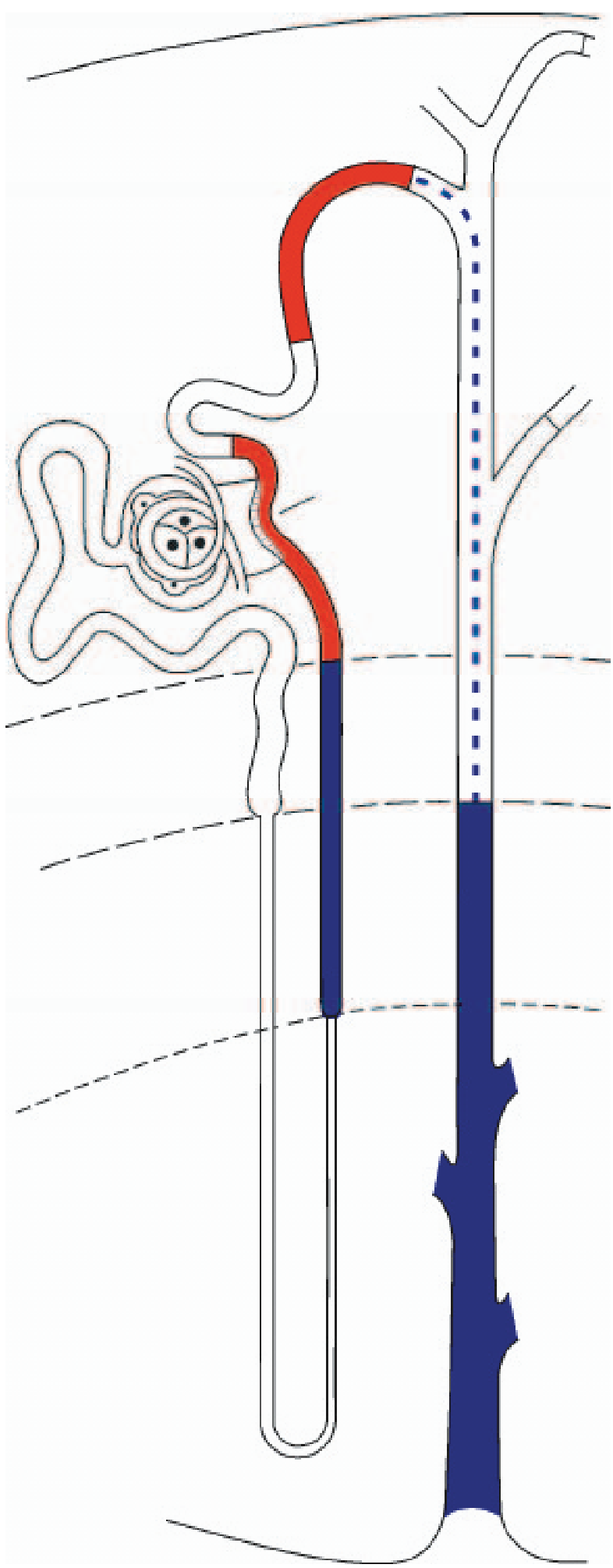

Figure 5 Schematic representation of the distribution of hepcidin immunoreactivity along the mammalian nephron and collecting duct system. Strong (red), intermediate (blue) and weak (broken blue line) staining intensities are indicated. the apical cell pole. This peculiar distribution pattern of hepcidin at the cellular level may assume a luminally directed release of hepcidin. We did not detect hepcidin immunoreactivity at the blood-side basal pole of renal tubule cells, suggesting that renal hepcidin is not released into the blood by these epithelial cells lining the tubules.

It is widely believed that control of iron homeostasis of the body is mainly dependent on tight regulation of iron uptake from the diet in the proximal small intestine. However, recent studies have shown that the kidney plays an important role in iron homeostasis (Gunshin et al. 1997, Ferguson et al. 2003, Wareing et al. 2003). Wareing et al. (2000) convincingly demonstrated that a metabolically significant amount of iron is filtered at the glomerulus and only $0 \cdot 8-1 \cdot 5 \%$ of the filtered iron is actually excreted in the urine. Thus, there must be a very effective pathway and a distinct regulation for reabsorption of iron along the renal tubules. Indeed, Ferguson et al. (2001) localized the divalent metal transporter 1 (DMT-1) in the tubular system of the kidney; this protein is proposed to be the major pathway for uptake of dietary iron by the gastrointestinal tract (Gunshin et al. 1997). Notably, DMT-1 expression has been shown to be highest at the apical pole of epithelial cells of distal tubules and collecting ducts, where we also found hepcidin. Furthermore, recent studies have demonstrated that altered dietary iron intake strongly modulates the renal DMT-1 expression (Wareing et al. 2003). Based on these findings, we believe that hepcidin is involved in a sophisticated regulation of renal iron transport.

The potential release of hepcidin into the urine was substantiated by immunoblot and ELISA studies. The region-specific hepcidin antisera coincidentally identified a strong immunoreactive band of the correct molecular mass (Kulaksiz et al. 2004) in urine that co-migrated with the immunoreactive hepcidin of kidney tissue extracts. These findings propose that hepcidin is synthesized by epithelial renal tubule and duct cells and suggest that it is released luminally into the urine where it apparently escapes tubular proteolysis and recycling. The possibility that the hepcidin seen in the kidney could be a consequence of filtration of the small circulating peptide cannot be totally excluded, however, our RT-PCR experiments show that hepcidin is intrinsically produced in the kidney.

To measure the pro-hepcidin concentration in human urine, a sensitive ELISA with a detection sensitivity of $\sim 4 \mathrm{ng} /$ well was developed. ELISA analyses with the hepcidin antiserum EG(2)-HepN, which was already successfully used in previous ELISA studies (Kulaksiz et al. 2004), revealed a high concentration of pro-hepcidin in the range from 13.9 to $456.0 \mathrm{ng} / \mathrm{ml}$ (means \pm S.E.; $180 \cdot 1 \pm 94 \cdot 8 \mathrm{ng} / \mathrm{ml}$ ) in the urine of healthy subjects. The mean concentration in urine is considerably higher than the pro-hepcidin mean concentration in the serum of these subjects $(68 \cdot 5-139 \cdot 2 \mathrm{ng} / \mathrm{ml}$; means \pm S.E., $104 \cdot 2 \pm$ $19 \cdot 5 \mathrm{ng} / \mathrm{ml})$. Notably, no correlation was found between 
the circulating pro-hepcidin and the serum iron or ferritin levels (Kulaksiz et al. 2004), nor between circulating pro-hepcidin and urinary pro-hepcidin. Likewise, no correlation was detected between urinary pro-hepcidin and serum iron or ferritin levels (data not shown), which are thought to regulate the expression of liver hepcidin (Pigeon et al. 2001, Nemeth et al. 2002, Ganz 2003). We therefore suggest that the regulation of renal/urinary pro-hepcidin is not directly influenced by serum iron or ferritin.

The evaluation of pro-hepcidin regulation in renalinsufficient patients undergoing chronic hemodialysis revealed that mean concentrations of pro-hepcidin in the serum of these patients were significantly increased from $104 \cdot 2 \mathrm{ng} / \mathrm{ml}$ in healthy subjects to $156 \cdot 8 \mathrm{ng} / \mathrm{ml}$. Enhanced levels of pro-hepcidin in dialysis patients suggests that the kidneys are not only involved in the synthesis of hepcidin, but that they may also be involved in the elimination of the circulating peptide. Interestingly, in a previous study, the kidney hormone erythropoietin was shown to downregulate the liver hepcidin gene expression (Nicolas et al. 2002b). Thus, another explanation for the enhanced pro-hepcidin concentrations in dialysis patients could be the relative deficiency of erythropoietin which is encountered regularly in terminal renal insufficiency (Eckardt 2000, Santoro 2002). However, enhanced levels of pro-hepcidin were measured in our patients with chronic renal insufficiency, although they were treated with the hepcidin inhibitory hormone erythropoietin, supporting the concept of renal filtration of hepcidin. Based on our present findings, we assume that urinary hepcidin originates partly from the kidney and partly from the liver.

In summary, we have localized the peptide hormone hepcidin in the kidney of three mammalian species, indicating that hepcidin is not liver specific. Besides its elimination in the kidney, hepcidin is also produced as an intrinsic peptide in the epithelial tubule and duct cells of the kidney and may be released luminally into the urine, implicating a regulatory role for hepcidin in the kidney and/or urinary tract. Further studies are needed to analyze the regulatory mechanism of hepcidin in the renal tubular system.

\section{Acknowledgements}

We thank Dr M Franke for providing blood from patients with chronic renal insufficiency. The technical assistance of K Bents (University Hospital Heidelberg) is greatly acknowledged. This study was supported by the Deutsche Forschungsgemeinschaft (KU 1253/5-1) and by the Forschungsforderungs-Programm of the University Hospital Heidelberg (8/2001, 76/2002, 58 and 79/2003). The authors declare that there is no conflict of interest that would prejudice the impartiality of this scientific work.

\section{References}

Bachmann S, Bostanjoglo M, Schmitt R \& Ellison DH 1999 Sodium transport-related proteins in the mammalian distal nephron distribution, ontogeny and functional aspects. Anatomical Embryology $200447-468$.

Brenner BM 2000 Anatomy of the kidney. In Brenner and Rector's The Kidney, edn 6, pp 3-67. Ed. BM Brenner. Philadelphia: WB Saunders Company.

Bridle KR, Frazer DM, Wilkins SJ, Dixon JL, Purdie DM, Crawford DH, Subramaniam VN, Powell LW, Anderson GJ \& Ramm GA 2003 Disrupted hepcidin regulation in HFE-associated haemochromatosis and the liver as a regulator of body iron homoeostasis. Lancet 361 669-673.

Campean V, Kricke J, Ellison D, Luft FC \& Bachmann S 2001 Localization of thiazide-sensitive $\mathrm{Na}(+)-\mathrm{Cl}(-)$ cotransport and associated gene products in mouse DCT. American Journal of Physiology - Renal Physiology 281 F1028-F1035.

Eckardt KU 2000 Pathophysiology of renal anemia. Clinical Nephrology $53 \mathrm{~S} 2-\mathrm{S} 8$.

Ferguson CJ, Wareing M, Ward DT, Green R, Smith CP \& Riccardi D 2001 Cellular localization of divalent metal transporter DMT-1 in rat kidney. American Journal of Physiology - Renal Physiology 280 F803-F814.

Ferguson CJ, Wareing M, Delannoy M, Fenton R, McLarnon SJ, Ashton N, Cox AG, McMahon RF, Garrick LM, Green R, Smith CP \& Riccardi D 2003 Iron handling and gene expression of the divalent metal transporter, DMT1, in the kidney of the anemic Belgrade (b) rat. Kidney International 64 1755-1764.

Ganz T 2003 Hepcidin, a key regulator of iron metabolism and mediator of anemia of inflammation. Blood 102 783-788.

Gehrke SG, Kulaksiz H, Herrmann T, Riedel HD, Bents K, Veltkamp C \& Stremmel W 2003 Expression of hepcidin in hereditary hemochromatosis: evidence for a regulation in response to serum transferrin saturation and non-transferrin-bound iron. Blood 102 371-376.

Gunshin H, Mackenzie B, Berger UV, Gunshin Y, Romero MF, Boron WF, Nussberger S, Gollan JL \& Hedinger MA 1997 Cloning and characterization of a mammalian proton-coupled metal-ion transporter. Nature 388 482-488.

Krause A, Neitz S, Magert HJ, Schulz A, Forssmann WG, Schulz-Knappe P \& Adermann K 2000 LEAP-1, a novel highly-disulfide bonded human peptide, exhibits antimicrobial activity. FEBS Letters 480 147-150.

Kulaksiz H, Schmid A, Hönscheid M, Ramaswamy A \& Cetin Y $2002 a$ Clara cell impact in air-side activation of CFTR in small pulmonary airways. PNAS 99 6796-6801.

Kulaksiz H, Rehberg E, Stremmel W \& Cetin Y $2002 b$ Guanylin and functional coupling proteins in the human salivary glands and gland tumors. Expression, cellular localization, and target membrane domains. American Journal of Pathology 161 655-664.

Kulaksiz H, Gehrke SG, Janetzko A, Rost D, Bruckner T, Kallinowski B \& Stremmel W 2004 Pro-hepcidin: expression and cell-specific localization in the liver and its regulation in hereditary hemochromatosis, chronic renal insufficiency, and renal anemia. Gut 53 735-743.

Nemeth E, Valore EV, Territo M, Schiller G, Lichtenstein A \& Ganz T 2002 Hepcidin, a putative mediator of anemia of inflammation, is a type II acute-phase protein. Blood 101 2461-2463.

Nicolas G, Bennoun M, Devaux I, Beaumont C, Grandchamp B, Kahn A \& Vaulont S 2001 Lack of hepcidin gene expression and severe tissue iron overload in upstream stimulatory factor 2 (USF2) knockout mice. PNAS 98 8780-8785.

Nicolas G, Bennoun M, Porteu A, Mativet S, Beaumont C, Grandchamp B, Sirito M, Sawadogo M, Kahn A \& Vaulont S $2002 a$ Severe iron deficiency anemia in transgenic mice expressing liver hepcidin. PNAS 99 4596-4601. 
Nicolas G, Viatte L, Bennoun M, Beaumont C, Kahn A \& Vaulont S $2002 b$ Hepcidin, a new iron regulatory peptide. Blood Cells, Molecules, and Diseases 29 327-335.

Park CH, Valore EV, Waring AJ \& Ganz T 2001 Hepcidin, a urinary antimicrobial peptide synthesized in the liver. Journal of Biological Chemistry 276 7806-7810.

Pigeon C, Ilyin G, Courselaud B, Leroyer P, Turlin B, Brissot P \& Loreal O 2001 A new mouse liver-specific gene, encoding a protein homologous to human antimicrobial peptide hepcidin, is overexpressed during iron overload. Journal of Biological Chemistry 276 7811-7819.

Roetto A, Papanikolaou G, Politou M, Alberti F, Girelli D, Christakis J, Loukopoulos D \& Camaschella C 2003 Mutant antimicrobial peptide hepcidin is associated with severe juvenile hemochromatosis. Nature Genetics 33 21-22.

Santoro A 2002 Anemia in renal insufficiency. Review of Clinical Experimental Hematology Suppl 1 12-20.
Tian W, Salanova M, Xu H, Lindsley JN, Oyama TT, Anderson S, Bachmann S \& Cohen DM 2004 Renal expression of osmotically responsive cation channel TRPV4 is restricted to water-impermeant nephron segments. American Journal of Physiology - Renal Physiology 287 F17-F24.

Wareing M, Ferguson CJ, Green R, Riccardi D \& Smith CP 2000 In vivo characterization of renal iron transport in the anaesthetized rat. Journal of Physiology 524 581-586.

Wareing M, Ferguson CJ, Delannoy M, Cox AG, McMahon RF, Green R, Riccardi D \& Smith CP 2003 Altered dietary iron intake is a strong modulator of renal DMT1 expression. American Journal of Physiology - Renal Physiology 285 F1050-F1059.

Received in final form 27 October 2004

Accepted 27 October 2004 